\title{
Cobertura retrátil no crescimento de mudas clonais de eucalipto ${ }^{1}$
}

\author{
Retractable cover on the growth of cloned cuttings of eucalyptus
}

\author{
Glauciana da Mata Ataide ${ }^{2 *}$, Renato Vinícius Oliveira Castro², Caroline Guieiro Correia ${ }^{2}$, Ana Flávia Neves \\ Mendes Castro ${ }^{2}$ e Reynaldo Campos Santana ${ }^{3}$
}

\begin{abstract}
Resumo - O sucesso na implantação de povoamentos florestais depende, em grande parte, do desempenho das mudas em resposta às variações no ambiente do viveiro. Objetivou-se, neste trabalho, avaliar o crescimento e a qualidade de mudas clonais de eucalipto em resposta à utilização de cobertura retrátil nos canteiros de crescimento. O experimento foi conduzido no período de abril a julho de 2008, constituindo-se de um delineamento inteiramente casualizado em esquema fatorial $2 \times 6$, em dois ambientes (com cobertura retrátil e sem cobertura retrátil) e seis diferentes materiais genéticos. Foram avaliadas as características altura da parte aérea, diâmetro do colo e pesos de matéria seca de raízes, parte aérea e total das mudas. Os resultados indicaram que a utilização de cobertura retrátil influenciou positivamente no crescimento de mudas clonais de eucalipto, as quais exibiram maiores médias de altura e incremento em biomassa de raízes e total para a maioria dos clones testados, o que contribuiu para o desenvolvimento das plantas, que apresentaram qualidade satisfatória aos 55 dias.
\end{abstract}

Palavras-chave - Eucalipto. Mudas-qualidade. Parâmetros morfológicos. Engenharia florestal.

\begin{abstract}
The successful forest implementation depends, in large part, of the performance of cutting answering to changes in nursery environment. This study had as objective evaluate the eucalyptus cuttings growth and quality, answering the use of retractable cover on the growth area. The experiment was conducted from April to July 2008, constituting a completely randomized design in a 2 x 6 factorial schem, in two locations (one with the retractable cover and the other without a retractable cover) and with six different genetic materials. Were evaluated the characteristics of shoot height, stem diameter and dry weights of roots, shoot and total of cuttings. The results indicated that the use of retractable cover positively influenced the eucalyptus cuttings growth, which exhibited highest average of height and increasing in root and total biomass, for the most tested clones, that contributed to the development of the plants, which showed good quality on the 55 th day.
\end{abstract}

Key words - Eucalyptus. Seedlings-quality. Morphological parameters. Forestry.

\footnotetext{
* Autor para correspondência

${ }^{1}$ Recebido para publicação em 13/05/2010; aprovado em 13/04/2011

Trabalho desenvolvido por alunos e professor da UFVJM para fins de publicação

${ }^{2}$ Programa de Pós-Graduação em Ciência Florestal, Universidade Federal de Viçosa, Av. PH Rolfs, s/n, Viçosa-MG, Brasil, 36.570-000,

glaucianadamata@yahoo.com.br, castrorvo@ymail.com, aguieirocorreia@yahoo.com.br, mendesafn@hotmail.com

${ }^{3}$ Departamento de Engenharia Florestal, Universidade Federal dos Vales do Jequitinhonha e Mucuri, Rua da Glória, n 187, Diamantina-MG, Brasil,

39.100-000, silviculturaufvjm@yahoo.com.br
} 


\section{Introdução}

As plantações de eucalipto no Brasil ocupam cerca de 4,3 milhões de hectares, o que representa, aproximadamente, $0,7 \%$ da superfície terrestre do país (ABRAF, 2009). A utilização de matéria-prima de origem florestal aumentou significativamente a partir da década de 60 , com a criação da política governamental de incentivos fiscais, e, desde então, a grande demanda pelos produtos florestais tem impulsionado um planejamento mais criterioso nas diversas etapas do processo de produção (MELLO et al., 2005).

A qualidade das mudas é um fator decisivo na implantação florestal, visto que mudas de boa qualidade apresentam crescimento satisfatório e elevada taxa de sobrevivência após o plantio (BARROSO et al., 2000; FINGER et al., 2003; SCHIAVO; MARTINS, 2003). A diversidade de regimes de crescimento das mudas em viveiro pode produzir mudas com diferentes qualidades (GARCIA et al., 2010; SANTOS et al., 2006; SILVA et al., 2007), e essas diferenças afetam o desempenho pósplantio, em termos de sobrevivência e crescimento no campo (DEL CAMPO et al., 2010).

O fornecimento de condições ambientais adequadas ao crescimento das mudas possibilita a expressão do potencial genético e o melhor aproveitamento dos recursos de crescimento (KOZLOWSKI et al., 1991). Contribui também nos processos fisiológicos essenciais às plantas, tais como: fotossíntese, abertura estomática e síntese de clorofila (CAMPOS, 1970). Diante da importância desse cenário, estratégias para o melhor aproveitamento das condições ambientais no viveiro tornam-se necessárias, de forma a conduzir à busca de novas tecnologias como alternativa para a produção de mudas de qualidade.

A cobertura retrátilnaárea destinada ao crescimento das mudas é apresentada como uma forma de otimizar a radiação solar, pois, quando aberta, permite à luz incidir diretamente na muda, garantindo, consequentemente, um melhor desempenho. Quando fechada, possibilita o controle das variações climáticas sobre as mudas, como: chuva, granizo, geada e temperatura. Além disto, tem-se a continuidade do trabalho em qualquer estação do ano, facilitando a obtenção de mudas de qualidade em tempo hábil e intervalos constantes. Porém, ainda é pouco utilizada no Brasil, devido ao alto custo e, provavelmente, à falta de informações sobre seu efeito no crescimento das mudas.

O objetivo deste trabalho foi avaliar o crescimento e qualidade de mudas clonais de diferentes híbridos Eucalyptus grandis x Eucalyptus urophylla em resposta à utilização de cobertura retrátil nos canteiros de crescimento.

\section{Material e métodos}

O experimento foi realizado em um viveiro de produção de mudas localizado no município de Belo Oriente, MG, entre abril e julho de 2008. O clima predominante na região é do tipo subtropical, com inverno seco e estação chuvosa no verão ( $\mathrm{CW}$, segundo a classificação de Köppen). Apresenta temperatura média anual de $22{ }^{\circ} \mathrm{C}$, $67 \%$ de umidade relativa do ar, precipitações médias anuais variando entre 701 e $1500 \mathrm{~mm}$ e altitude de $240 \mathrm{~m}$.

Para a produção das mudas de eucalipto, miniestacas com dimensões variando de 4 a $6 \mathrm{~cm}$ foram coletadas nos minijardins clonais e estaqueadas pelo método da miniestaquia. Como recipientes para as mudas, foram utilizados tubetes de plástico com $55 \mathrm{~cm}^{3}$ de capacidade, contendo substrato constituído de partes iguais de vermiculita de granulometria média e casca de arroz carbonizada, além de fertilização de base (TAB. 1). A irrigação e a nutrição mineral das mudas foram efetuadas através de um sistema automatizado de fertirrigação por inundação.

Tabela 1 - Fertilização aplicada no substrato usado para produção de mudas de eucalipto

\begin{tabular}{ccc}
\hline Fertilizante & Dose $\left(\mathrm{kg} \mathrm{m}^{-3}\right)$ & $\begin{array}{c}\text { Forma de } \\
\text { Aplicação }\end{array}$ \\
\hline Superfosfato simples & 8,000 & Direta \\
Sulfato de amônio & 0,695 & Via solução \\
Cloreto de potássio & 0,208 & Via solução \\
Sulfato de zinco & 0,014 & Via solução \\
Sulfato de cobre & 0,014 & Via solução \\
Sulfato de manganês & 0,014 & Via solução \\
Ácido bórico & 0,021 & Via solução \\
\hline
\end{tabular}

As mudas foram mantidas em casa de vegetação durante 20 dias para o enraizamento. Posteriormente, deixadas em casa de sombra por cinco dias e então levadas para a área de crescimento.

$\mathrm{O}$ experimento foi instalado em um delineamento inteiramente casualizado, disposto no esquema fatorial ( $2 \times 6)$. Os tratamentos foram constituídos por duas condições de cobertura dos canteiros de mudas na área de crescimento ( $\mathrm{T} 1$ - com utilização de cobertura retrátil; T2 - sem utilização de cobertura retrátil) e mudas de seis clones híbridos de Eucalyptus grandis $\mathrm{x}$ Eucalyptus urophylla. A cobertura utilizada consiste de um teto translúcido $100 \%$ retrátil, fabricado em plástico transparente e cobrindo totalmente os canteiros. 
Aos 55 dias após o estaqueamento, foram realizadas as avaliações dos parâmetros morfológicos das mudas. A altura da parte aérea $(\mathrm{H})$ das mudas foi mensurada com auxílio de uma régua milimetrada posicionada em nível do substrato até o meristema apical da muda, enquanto o diâmetro do colo (DC) foi medido com paquímetro digital. O material vegetal foi dividido em parte aérea (folhas e caule) e raiz, sendo o sistema radicular separado do substrato por meio de lavagem com água. Em seguida, o material foi acondicionado em sacos de papel e conduzido à estufa com circulação forçada de ar, a $65^{\circ} \mathrm{C}$, até atingir massa constante, sendo então pesado em balança de precisão para as determinações da matéria seca da parte aérea (MSPA), matéria seca das raízes (MSR) e matéria seca total (MST). De posse dos valores de MSPA e MSR, foram calculadas as relações entre matéria seca da parte aérea e matéria seca das raízes (MSPA/MSR).

A relação entre MSPA e MSR foi avaliada pelo método gráfico a partir da transformação logarítmica das variáveis em $(\operatorname{Ln}(\mathrm{x}))$, utilizando-se como critério o modelo de equilíbrio entre o crescimento de parte aérea e das raízes proposto por Wilson (1988), no qual tendências mais próximas a $45^{\circ}$ indicam melhor alocação da biomassa pelas plantas.

Para a avaliação das características H e DC, foram utilizadas 20 repetições por tratamento, enquanto para a determinação de MSR, MSPA e MST, foram utilizadas seis repetições, sendo cada muda considerada uma repetição.

Os dados foram submetidos aos testes de Lilliefors e Cochran para testar a normalidade e homogeneidade das variâncias, respectivamente. Em seguida, procedeu-se à análise de variância pelo teste F, sendo as médias comparadas pelo teste Tukey. Para a variável DC, foi utilizado o teste não-paramétrico de Kruskall-Wallis, por esta não apresentar homogeneidade das variâncias. Considerou-se sempre o nível de significância de 5\%. As análises estatísticas foram realizadas com o auxílio do programa STATISTICA 8.0.

\section{Resultados e discussão}

A utilização de cobertura retrátil na área destinada ao crescimento de mudas no viveiro influenciou positivamente o crescimento em $\mathrm{H}$ das mudas clonais de eucalipto, as quais apresentaram médias de $\mathrm{H}$ estatisticamente superiores às médias das mudas cultivadas sem a cobertura para os clones 1; 2 e 4. Para os demais materiais genéticos, resultados semelhantes foram observados nos dois locais (FIG. 1). Pode-se inferir que as condições de maior controle ambiental fornecidas pela cobertura resultaram em uma uniformidade no crescimento em $\mathrm{H}$ das mudas, haja vista que não houve diferença significativa entre os clones dentro deste local. Segundo Campos (1970), desde que as condições não sejam limitantes, as plantas aumentam suas possibilidades de expressão hereditária, crescendo ao longo do tempo.

A H é uma característica de fácil medição nas mudas e, por isso, sempre foi utilizada para estimar o padrão de qualidade nos viveiros (GOMES et al., 2003), sendo considerada também como um dos mais importantes parâmetros para estimar o crescimento no campo pós-plantio (REIS et al., 2008), além de que a avaliação de $\mathrm{H}$ não acarreta a destruição das mudas, sendo tecnicamente aceita como uma boa medida do potencial de desempenho das mesmas.

Espera-se que plantas maiores, em mesma idade cronológica, tenham maiores reservas de assimilados (KOZLOWSKI et al., 1991), e alturas superiores da parte aérea implicam em maior área foliar disponível para a fotossíntese e transpiração, sendo uma vantagem em sítios onde a competição entre plantas poderá ser um problema (GOMES et al., 2002). Entretanto, através do uso da fertilização nitrogenada pode ocorrer maior crescimento em $\mathrm{H}$ sem necessariamente um fortalecimento fisiológico da muda (CARNEIRO, 1995).

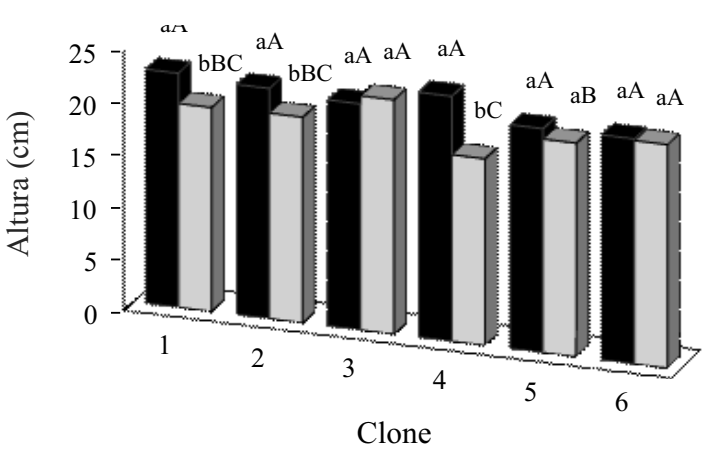

Médias seguidas da mesma letra maiúscula entre os clones e minúscula entre os tratamentos T1 e T2 não diferem entre si, a 5\% de significância, pelo teste Tukey

Figura 1 - Altura da parte aérea $(\mathrm{H})$ de mudas clonais de Eucalyptus nos locais com cobertura retrátil e sem cobertura retrátil, aos 55 dias após o estaqueamento 
(A)

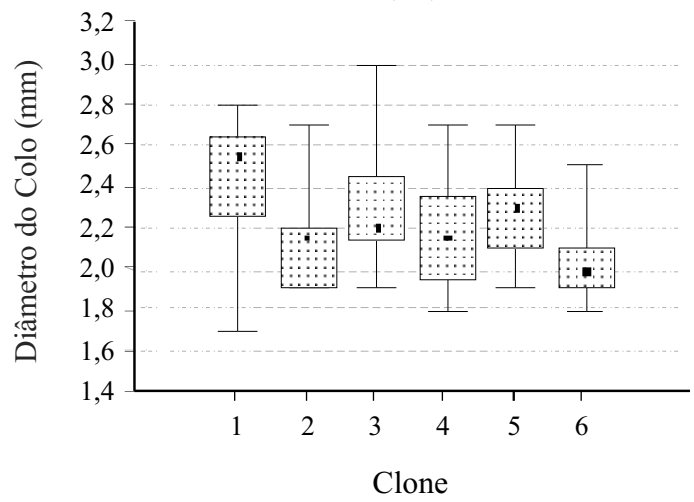

(B)

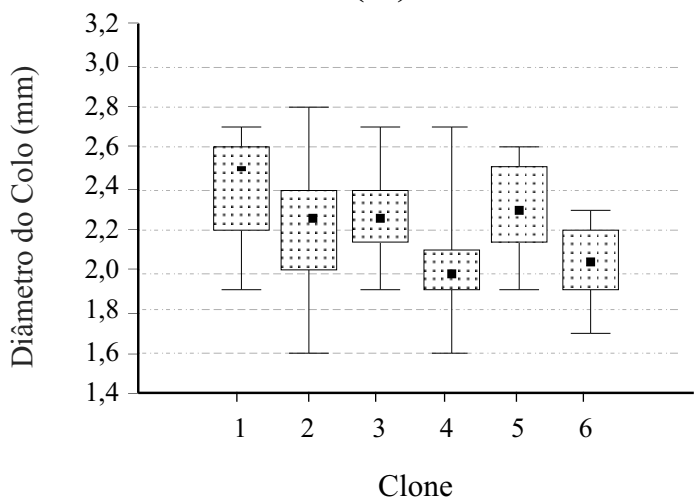

Média

$$
\text { ... 25\%-75\% 工 Min-Máx }
$$

Figura 2 - Diâmetro do colo (DC) de mudas clonais de Eucalyptus para os seis Clones avaliados: (A) T1 - local com cobertura retrátil; (B) T2 - local sem cobertura retrátil

Para o DC, o desempenho das mudas foi similar nos dois ambientes, não havendo diferença significativa entre as médias pelo teste de comparação múltipla não-paramétrica (FIG. 2). Comparando os materiais genéticos utilizados, o Clone 1 apresentou os maiores valores de DC das mudas, seguido dos Clones 3 e 5. Mudas de Hymenaea parvifolia, Maclura tinctoria, Jacaranda copaia e Hymenaea courbaril também não apresentaram diferenças nessa variável quando cultivadas em ambientes com sombreamento artificial e a pleno sol (ALMEIDA et al., 2005; CAMPOS; UCHIDA, 2002; SILVA et al., 2007).

O crescimento em diâmetro apresenta uma relação direta com as taxas de assimilação líquida de produtos da fotossíntese (GONÇALVES et al., 2000), estimulada a partir de carboidratos produzidos e hormônios translocados das regiões apicais após as plantas terem atingido um tamanho adequado (KOZLOWSKI et al., 1991). Na avaliação de mudas de eucalipto, valores de diâmetro do colo acima de 2,0 mm são desejáveis para a expedição (FREITAS et al., 2006; GOMES et al., 2003; SOUZA et al., 2006).

Analisando as médias da biomassa acumulada pela planta e sua repartição em raiz e parte aérea, observa-se que houve interação entre os fatores analisados, e maiores valores de MSR foram encontrados nas mudas produzidas no ambiente com cobertura retrátil, exceto para o Clone 4 (FIG. 3A). Fonseca et al. (1979) constataram haver uma tendência de decréscimo na proporção de biomassa radicular das mudas de Eucalyptus grandis à medida que a luz se torna menos disponível, indicando adequados sombreamentos de até $25 \%$ para a espécie. De acordo com Toumey e Korstian (1962), a quantidade de matéria seca produzida aumenta com a intensidade de luz até um máximo, decrescendo posteriormente. Mudas com maior percentual de raízes apresentam maior resistência a condições de estresse ambiental (FREITAS et al., 2005), por possuírem maior superfície de absorção e favorecerem a fixação das plantas no solo, com fundamental importância na sobrevivência e crescimento pós-plantio (CARNEIRO, 1995). Dessa forma, a MSR é considerada importante para estimar o crescimento inicial das mudas em campo (GOMES et al., 2002), visto que a habilidade das plantas em absorver água e nutrientes minerais do solo está relacionada à sua capacidade de desenvolver um vigoroso sistema radicular (TAIZ; ZEIGER, 2009).

A MSPA das mudas de eucalipto apresentou valores equivalentes nos dois locais estudados, com diferença significativa apenas para as mudas dos Clones 1 e 4 (FIG. 3B). Uma maior proporção de biomassa alocada para os órgãos aéreos otimiza o processo fotossintético, ao aumentar a eficiência na captação de luz pelas plantas (CHAPIN et al., 1987). Além disso, a quantidade e qualidade das folhas constituem fontes de nutrientes para a adaptação das mudas, que necessitarão de boa reserva de fotoassimilados como suprimento de água e nutrientes para as raízes no primeiro mês de plantio (BELLOTE; SILVA, 2000).

A utilização da cobertura retrátil também favoreceu o incremento em MST das mudas clonais de eucalipto para os clones 1; 3 e 6 (FIG. 3C). O 

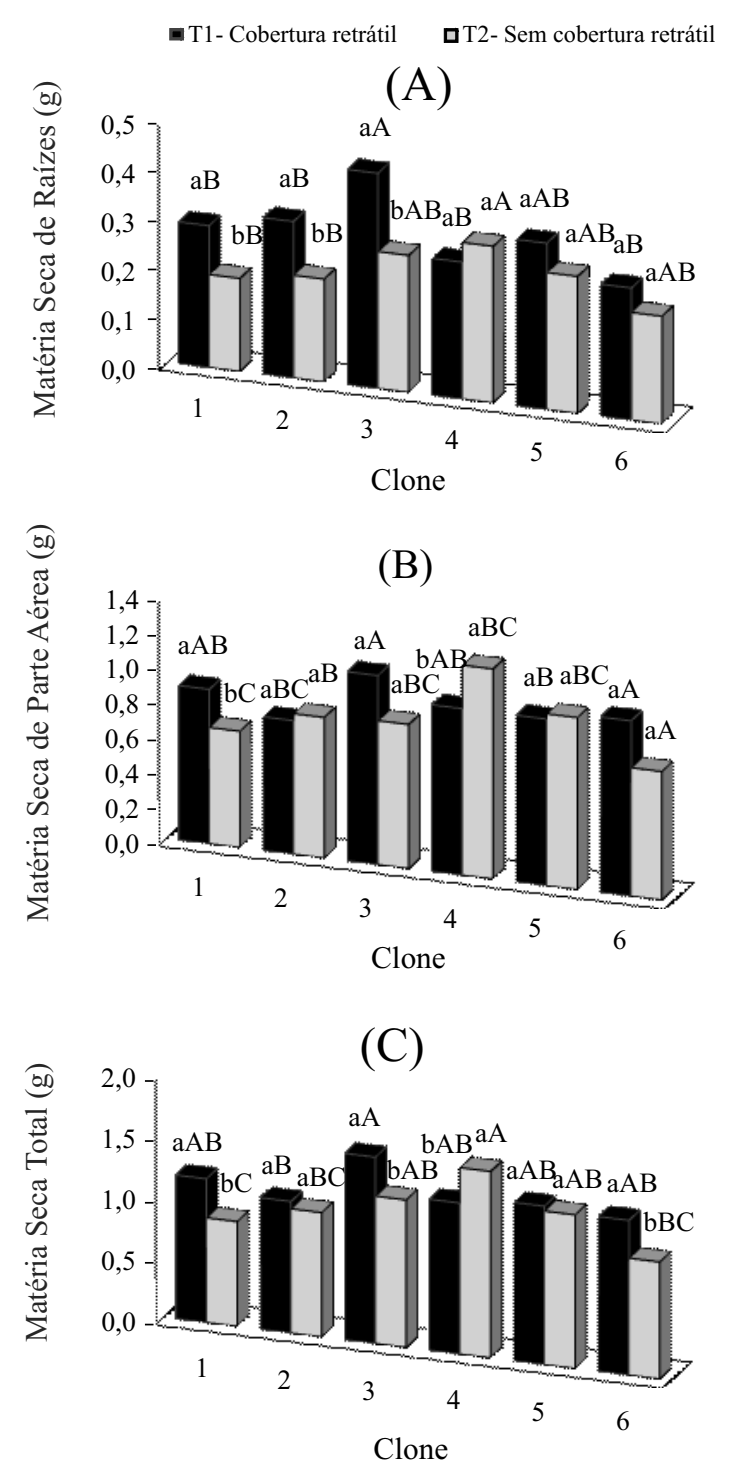

Médias seguidas da mesma letra maiúscula entre os clones e minúscula entre os tratamentos T1 e T2 não diferem entre si, a 5\% de significância, pelo teste Tukey

Figura 3 - Matéria seca de raízes (MSR) (A) matéria seca de parte aérea (MSPA) (B) e matéria seca total (MST) (C) de mudas clonais de Eucalyptus nos locais com cobertura retrátil e sem cobertura retrátil, aos 55 dias após o estaqueamento

ganho de biomassa pelas plantas cultivadas no local com cobertura indica ser este apropriado para a produção das mudas de eucalipto desses materiais genéticos. Maior incremento em MST é resultado de plantas mais eficientes (BARRETTO et al., 2007), ao realizarem a adequada conversão do carbono em quantidades crescentes de carboidratos, sendo o crescimento decorrente do acúmulo dessas substâncias pelos vegetais (LARCHER, 2000). Dessa forma, a luz é um fator ambiental que controla os processos associados ao acúmulo de matéria seca, contribuindo para o crescimento vegetal (LIMA et al., 2008), porém o excesso de luz pode ser potencialmente estressante para as plantas (KRAMER; KOZLOWSKI, 1960).

Ide e Kageyama (1980) indicam o fator sombra como importante para a produção de mudas de Eucalyptus cloeziana, principalmente, em níveis de $50 \%$ de sombreamento, que apresentaram valores superiores a $90 \%$ de sombreamento e a testemunha, a pleno sol. Analisando mudas de Pinus insularis, Ferreira et al. (1981) também observaram que sombreamentos acima de $50 \%$ prejudicaram a produção de massa seca total das plantas, as quais possuem baixa capacidade de adaptação a menores intensidades de luz.

A MSPA/MSR apresentou valores mais próximos da tendência ideal no local com cobertura retrátil para todos os clones avaliados (FIG. 4), indicando melhor desenvolvimento da parte aérea e das raízes das plantas.

Segundo Benincasa (2003), essa relação expressa a quantidade de biomassa distribuída nas plantas. Existe um balanço ótimo na relação entre os logaritmos neperianos da matéria seca de parte aérea e sistema radicular em plantas sob condições ambientais não limitantes, ou "equilíbrio funcional", onde esta relação tende a apresentar valores próximos a 1 no crescimento normal da planta (POORTER; NAGER, 2000).

As mudas de eucalipto alocaram mais biomassa para a parte aérea em detrimento das raízes, em função, principalmente, da restrição causada pelo volume dos recipientes utilizados, o que reduz a quantidade de substrato explorável para o desenvolvimento do sistema radicular (FREITAS et al., 2006; GOMES et al., 2003; LELES et al., 2000).

De maneira geral, a utilização de cobertura retrátil mostrou-se favorável à produção de mudas clonais de eucalipto em viveiro, com resultados satisfatórios nas características morfológicas para a maioria dos materiais genéticos analisados. Considerando-se que a cobertura retrátil não promove o sombreamento das mudas em tempo integral, mas apenas por determinados períodos, esta pode ser mais bem aproveitada se fechada apenas nos momentos em que as condições ambientais não sejam favoráveis ao crescimento e aproveitamento de luz pelas plantas. 


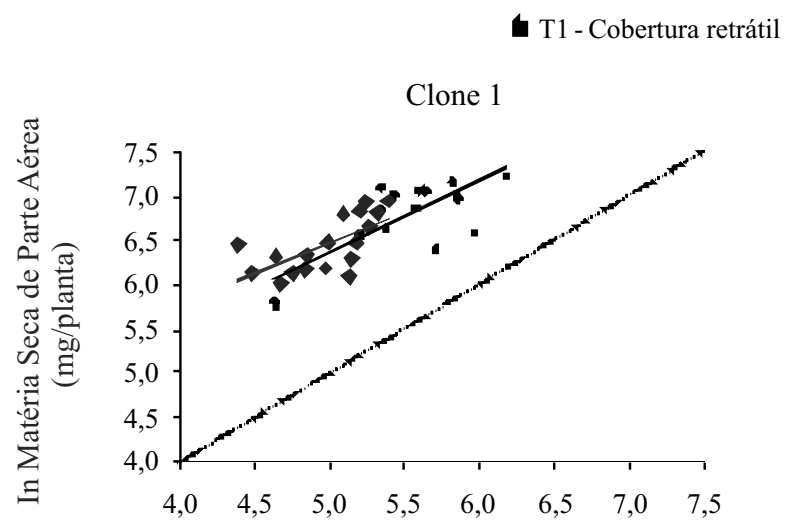

ln Matéria Seca de Raíz (mg/planta)

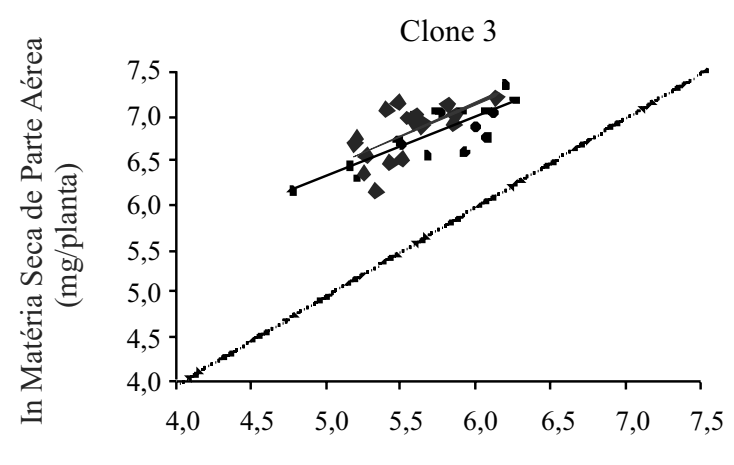

ln Matéria Seca de Raíz (mg/planta)

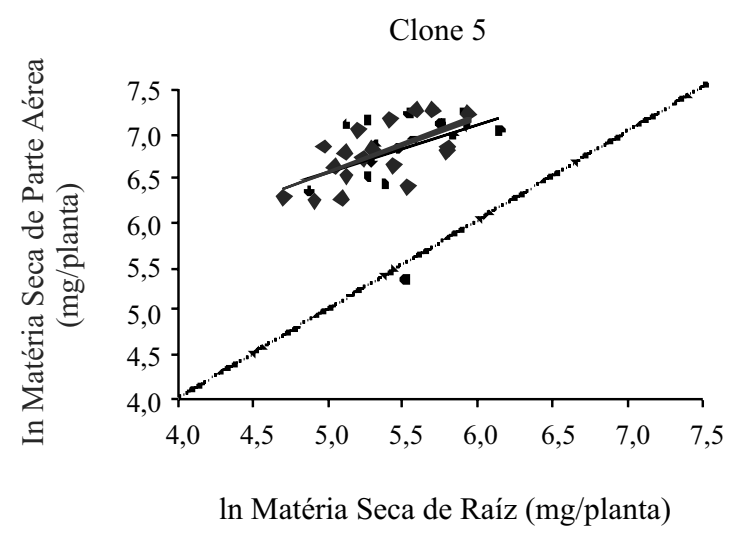

- T2 - Sem cobertura retrátil

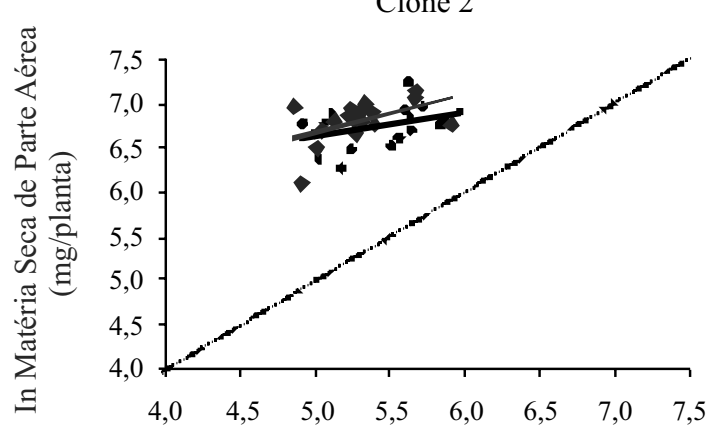

ln Matéria Seca de Raíz (mg/planta)

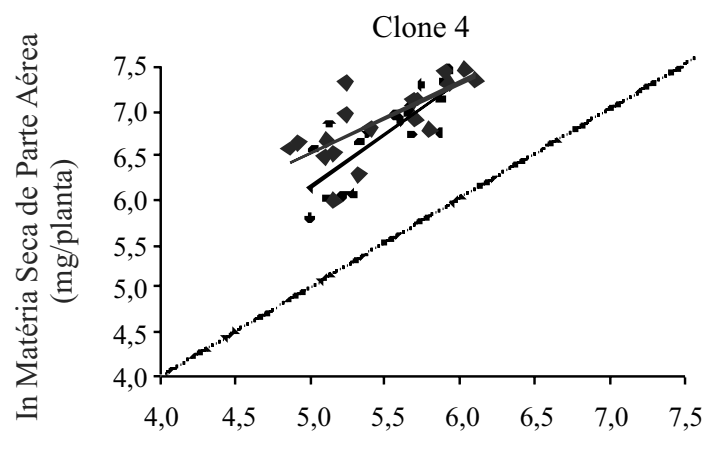

ln Matéria Seca de Raíz (mg/planta)

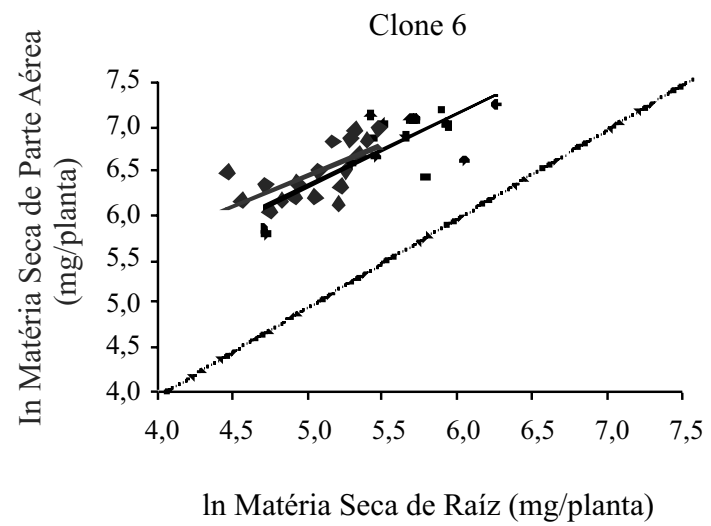

Figura 4 - Relação entre as variáveis transformadas para $\ln (\mathrm{x})$ de matéria seca da parte aérea (MSPA) e matéria seca de raízes (MSR) em mudas clonais de Eucalyptus aos 55 dias após estaqueamento

\section{Conclusão}

A utilização de cobertura retrátil influenciou positivamente no crescimento em altura e massa seca total e de raízes das mudas clonais de eucalipto, que apresentaram qualidade satisfatória aos 55 dias após o estaqueamento.

\section{Referências}

ASSOCIAÇÃO BRASILEIRA DE PRODUTORES DE FLORESTAS PLANTADAS (ABRAF). Anuário Estatístico da ABRAF: ano base 2008. Brasília, 2009. 90 p.

ALMEIDA, S. M. Z. et al. Alterações morfológicas e alocação de biomassa em plantas jovens de espécies florestais sob 
diferentes condições de sombreamento. Ciência Rural, v. 35 , n. 01 , p. 62-68, 2005.

BARRETTO, V. C. de M. et al. Eficiência de uso de boro no crescimento de clones de eucalipto em vasos. Scientia Forestalis, n. 76, p. 21-33, 2007.

BARroso, D. G.; CARNeIRO, J. G. A.; LELES, P. S. S. Qualidade de mudas de Eucalyptus camaldulensis e E. urophylla, produzidas em tubetes e em blocos prensados, com diferentes substratos. Floresta e Ambiente, v. 07, n. 01, p. 238-250, 2000.

BELlOTE, A. F. J.; SILVA, H. D. Técnicas de amostragem e avaliações nutricionais em plantios de Eucalyptus spp. In: GONÇALVES, J. L. M.; BENEDETTI, V. Nutrição e fertilização florestal. Piracicaba: IPEF, 2000. p. 105-133.

BENINCASA, M. M. P. Análise de crescimento de plantas (noções básicas). 2. ed. Jaboticabal: FUNEP, 2003. 41 p.

CAMPO, A. D.; NAVARRO, R. M.; CEACERO, C. J. Seedling quality and field performance of commercial stocklots of containerized holm oak (Quercus ilex) in Mediterranean Spain: an approach for establishing a quality standard. New Forests, v. 39, n. 01, p. 19-37, 2010.

CAMPOS, J. C. C. Principais fatores do meio que afetam o crescimento das árvores. Floresta, v. 02, n. 03, p. 45-52, 1970.

CAMPOS, M. A. A.; UCHIDA, T. Influência do sombreamento no crescimento de mudas de três espécies amazônicas. Pesquisa Agropecuária Brasileira, v. 37, n. 03, p. 281-288, 2002.

CARNEIRO, J. G. A. Produção e controle de qualidade de mudas florestais. Curitiba: UFPR/FUPEF; Campos: UENF, 1995. 451 p.

CHAPIN, F. S. et al. Plants responses to multiple environmental factors. Bioscience, v. 37, n. 01, p. 49-57, 1987.

FERREIRA, M. G. M. et al. Efeito do sombreamento e da densidade de sementes sobre o desenvolvimento de mudas de Pinus insulris Endlicher e seu crescimento inicial no campo. Revista Floresta, v. 02, n. 01, p. 53-57, 1981.

FINGER, C. A. G. et al. Estabelecimento de povoamentos de Pinus elliottii Engelm pela semeadura direta a campo. Ciência Florestal, v. 13, n. 01, p. 107-113, 2003.

FONSECA, A. G. da et al. Efeito do sombreamento, do tamanho e peso de sementes na produção de mudas de Eucalyptus grandis W. Hill ex Maiden e no seu crescimento inicial em campo. Revista Árvore, v. 03, n. 02, p. 145-159, 1979.

FREITAS, T. A. S. et al. Desempenho radicular de mudas de eucalipto produzidas em diferentes recipientes e substratos. Revista Árvore, v. 29, n. 06, p. 853-861, 2005.

FREITAS, T. A. S. et al. Mudas de eucalipto produzidas a partir de miniestacas em diferentes recipientes e substratos. Revista Árvore, v. 30, n. 04, p. 519-528, 2006.

GARCIA, G. de O. et al. dos. Crescimento de mudas de eucalipto submetidas à aplicação de biossólidos. Revista Ciência Agronômica, v. 41, n. 01, p. 87-94, 2010.
GOMES, J. M. et al. Crescimento de mudas de Eucalyptus grandis em diferentes tamanhos de tubetes e fertilização NP-K. Revista Árvore, v. 27, n. 02, p. 113-127, 2003.

GOMES, J. M. et al. Parâmetros morfológicos na avaliação da qualidade de mudas de Eucalyptus grandis. Revista Árvore, v. 26, n. 06, p. 655-664, 2002.

GONÇALVES, J. L. M. et al. Produção de mudas de espécies nativas: substrato, nutrição, sombreamento e fertilização. In: GONÇALVES, J. L. M.; BENEDETTI, V. Nutrição e fertilização florestal. Piracicaba: IPEF, 2000. cap.11, p. 310-315.

IDE, M. de L. C.; KAGEYAMA, P. Y. Efeito da luminosidade e profundidade de semeadura de Eucalyptus cloeziana. Circular Técnica IPEF, n. 100, 6 p., 1980.

KOZLOWSKI, T. T.; KRAMER, P. J.; PALLARDY, S. G. The physiological ecology of woody plants. San Diego: Academic Press, 1991. $657 \mathrm{p}$.

KRAMER, P. J.; KOZLOWSKI, T. T. Physiology of trees. New York: McGraw Hill, 1960. 642 p.

LARCHER, W. Ecofisiologia vegetal. São Carlos: RiMa Artes e Textos, 2000. $531 \mathrm{p}$.

LELES, P. S. et al. Qualidade de mudas de Eucalyptus spp. produzidas em blocos prensados e em tubetes. Revista Árvore, v. 24, n. 01, p. 13-20, 2000.

MELLO, A. A. de et al. Planejamento florestal visando à maximização dos lucros e a manutenção do estoque de carbono. Revista Cerne, v. 11, n. 03, p. 205-217, 2005.

POORTER, H.; NAGEL, O. The role of biomass in the growth response of plants to different levels of light, $\mathrm{CO} 2$, nutrients and water: a quantitative review. Australian Journal of Plant Phisiology, v. 27, n. 06, p. 595-607, 2000.

REIS, E. R. et al. Período de permanência de mudas de Eucalyptus grandis em viveiro baseado em parâmetros morfológicos. Revista Árvore, v. 32, n. 05, p. 809-814, 2008.

SANTOS, D. L. et al. Morphological and physiological responses of Cedrela fissilis Vellozo (Meliaceae) seedlings to light. Brazilian Archives of Biology and Technology, v. 49, n. 01, p. 171-182, 2006.

SCHIAVO, J. A.; MARTINS, M. A. Produção de mudas de acácia colonizadas com micorrizas e rizóbio em diferentes recipientes. Pesquisa Agropecuária Brasileira, v. 38, n. 02, p. 173-178, 2003.

SILVA, B. M. da S. et al. Efeito da luz no crescimento de mudas de Hymenaea parvifolia Huber. Revista Árvore, v. 31, n. 06, p. 1019-1026, 2007.

SOUZA, C. A. M. de et al. Crescimento em campo de espécies florestais em diferentes condições de adubações. Ciência Florestal, v. 16, n. 03, p. 243-249, 2006.

TAIZ, L.; ZEIGER, E. Fisiologia vegetal. 4. ed. Porto Alegre: Artmed, 2009. 848 p. 
TOUMEY, J. W.; KORSTIAN, C. F. Foundations of silviculture upon on ecological basis. New York: John Willey, 1962. $468 \mathrm{p}$.
WILSON, J. B. A review of evidence on the control of shoot: root ratio in relation to models. Annals of Botany, v. 61, n. 04, p. 433-449, 1988. 